\title{
FREQUENCY OF FABRY DISEASE IN A JUVENILE IDIOPATHIC ARTHRITIS COHORT
}

Luciana Paim-Marques ${ }^{1,2}$, Amanda Virginia Cavalcante ${ }^{3}$, Islane Verçosa ${ }^{4}$, Paula Carneiro ${ }^{4}$, Marcia Souto-Maior ${ }^{5}$, Erlane Marques ${ }^{1}$, Simone Appenzeller ${ }^{6, *}$

1.Hospital Infantil Albert Sabin, Fortaleza (CE), Brazil. 2.University of Florida, Gainesville (FL), USA. 3.Escola de Saúde Pública do Ceará, Fortaleza (CE), Brazil. 4.Instituto CAVIVER, Fortaleza (CE), Brazil. 5.Universidade de Fortaleza, Fortaleza (CE), Brazil. 6.Universidade Estadual de Campinas, Campinas (SP), Brazil.

${ }^{\star}$ Corresponding author: appenzellersimone@gmail.com

\section{BACKGROUND}

A doença de Fabry (DF) é um distúrbio de armazenamento lisossômico multissistêmico raro, ligado ao X, que resulta de uma deficiência na enzima alfa-galactosidase A ( Gal-A). A prevalência de DF entre pacientes com diagnóstico estabelecido de artrite idiopática juvenil (AIJ) é desconhecida, e a DF clássica tem início na infância com sintomas inespecíficos leves que podem afetar o sistema musculoesquelético. O objetivo deste trabalho foi identificar a frequência de DF em uma coorte de AlJ por sintomas clínicos precoces, títulos de enzimas e genotipagem de GLA.

\section{MATERIAL AND METHODS}

Foram selecionadas crianças com AlJ de uma coorte de um hospital infantil terciário. Informações clínicas, laboratoriais e familiares foram registradas. Testes genéticos moleculares para detectar variantes patogênicas no gene GLA foram realizados nas pacientes do sexo feminino e análises enzimáticas nos do sexo masculino.

\section{RESULTS}

Dos 89 pacientes (56,17\% do sexo feminino, início da doença: $8,93 \pm 4,35$ anos), um paciente do sexo masculino (1,12\%) apresentou variante patogênica no gene GLA (c.1244T>C; p.L415P), um paciente do sexo feminino apresentou variante de significado incerto: c.38C > T (p.Ala13Val). A atividade enzimática da aGal-A estava ligeiramente diminuída em outros três pacientes (3,36\%). Dois pacientes (2,24\%) apresentavam história e sintomas clínicos sugestivos de DF (dispepsia, hipohidrose, acroparestesia e dispepsia, dificuldade de ganho de peso, história familiar de morte súbita e doença renal em estágio terminal). O terceiro não apresentava sintomas relacionados à DF ou antecedentes familiares sugestivos. Observou-se a presença de $5(5,61 \%)$ pacientes com córnea verticilata, uma lesão corneana característica da DF. Num total de 89 pacientes, em 26 (29,21\%) foram identificadas alterações genéticas, sendo 24 (44,44\%) deles com polimorfismo intrônico de nucleotídeo único (SNP) c.1000-22C> T (rs2071228) no íntron 6, em 16 (61,53\%) com a variante c.370-81_- 77del (rs5903184) no íntron 2, em 15 (57,69\%) pacientes com a variante c.640-16A> G ( rs2071397) no íntron 4; em 8 (30,76\%) deles com c.-10C> T (rs2071225) no 5’UTR exon 1; em 7 (26,92\%) pacientes com a variante c.548-125C> G (rs2071396) no íntron 3 e, em 4 com a variante c.-12G> A (rs3027585) 5’UTR exon. Essas variantes apresentaram associações positivas com sintomas da DF isoladas ou combinadas em haplótipos intrônicos complexos (HIC).

\section{CONCLUSIONS}

A incidência da DF na presente coorte foi de 1,12\%. Também se observou HIC associados aos sintomas da DF em pacientes com AlJ. 